\title{
Expression and purification of SenX3 from the Mycobacterium tuberculosis strain H37Rv in Escherichia coli
}

\author{
HUOYANG LV ${ }^{1}$, LIQING HU ${ }^{2}$, QINGFENG HU ${ }^{1}$, QUHAO WEI ${ }^{1}$ and PEIQIONG SHEN ${ }^{1}$ \\ ${ }^{1}$ Center of Laboratory Medicine, Zhejiang Provincial People's Hospital, Hangzhou, Zhejiang 310014; \\ ${ }^{2}$ Department of Laboratory Medicine, The First Ningbo Hospital, Ningbo, Zhejiang 315000, P.R. China
}

Received November 6, 2012; Accepted April 11, 2013

DOI: $10.3892 / \mathrm{mmr} .2013 .1449$

\begin{abstract}
Infection with the bacterium Mycobacterium tuberculosis (MTB) causes tuberculosis, a pulmonary infection that may be fatal if left untreated. Misuse or mismanagement of tuberculosis drugs may lead to drug-resistant pathogen forms that are difficult to treat and contribute to a global health problem. The MTB SenX3/RegX3 signal transduction system allows bacteria to externally sense the environment and mediate an appropriate internal response; SenX3 is also associated with MTB virulence, suggesting that this protein may provide a potential therapeutic target. To investigate the role of SenX3 and MTB drug resistance, SenX3 was cloned, expressed and purified in Escherichia coli. SenX3 was cloned from the genome of the MTB strain H37Rv by polymerase chain reaction and an internal $N c o$ I restriction site was destroyed by site-directed mutagenesis to allow cloning into the pET-28b prokaryotic expression vector. SenX3 expression from the resulting $\mathrm{pET}-28 \mathrm{~b}-\mathrm{mSenX} 3$ plasmid was induced with isopropyl $\beta$-D-thiogalactoside and the protein was purified using Ni-NTA agarose affinity chromatography. A pure protein of the expected size was identified. The examination of purified SenX3 protein is considered to enable the in-depth investigation of SenX3-mediated drug resistance.
\end{abstract}

\section{Introduction}

Tuberculosis is a chronic infectious disease caused by Mycobacterium tuberculosis (MTB) infection $(1,2)$. Although drugs are capable of effectively treating tuberculosis, misuse or mismanagement of drug courses may lead to drug-resistant tuberculosis (DR-TB) or multidrug-resistant tuberculosis (MDR-TB). These drug-resistant disease forms are difficult to

Correspondence to: Dr Huoyang Lv, Center of Laboratory Medicine, Zhejiang Provincial People's Hospital, 158 Shangtang Road, Hangzhou, Zhejiang 310014, P.R. China

E-mail: lab_lhx1106@126.com

Key words: Mycobacterium tuberculosis, SenX3, prokaryotic expression, protein purification, tuberculosis treat and underlie a new global prevalence of tuberculosis $(3,4)$. A better understanding of MTB pathogenesis is required to ameliorate this threat.

Two-component signal transduction systems (TCSSs) are pathogen junction systems that monitor external environmental stimuli and coordinate cellular responses, particularly the modulation of gene expression. TCSSs are important bacterial mechanisms for pathogenesis (5) and typically consist of two proteins; a transmembrane histidine kinase and a corresponding cytoplasmic response regulator. The MTB genome encodes 30 TCSS proteins (6), several of which are strongly associated with MTB drug resistance $(4,5)$. Thus, inhibiting TCSSs of resistant bacteria may be an effective strategy to combat DR-TB and MDR-TB. SenX3/RegX3 was the first MTB TCSS to be reported, where SenX3 is a transmembrane histidine kinase and RegX 3 is the corresponding DNA-binding response regulator (6). SenX3 is associated with MTB virulence and, thus, its investigation may further elucidate the molecular mechanisms of MTB drug resistance (7-9).

In the present study, we purified the MTB strain H37Rv recombinant SenX3 following expression in Escherichia coli (E. coli) in order to provide reagents for the future investigation of SenX3 and its role in MTB pathogenesis.

\section{Materials and methods}

Cloning of MTB strain H37Rv SenX3 into pMD18-T. According to the published sequence (GenBank accession no. Y13628.1), the primers were designed to incorporate an NcoI restriction site upstream and an XhoI restriction site downstream of SenX3 in the genomic DNA of the MTB strain H37Rv, which was provided by Dr Wen-Tao Shen (Chinese Academy of Tropical Agricultural Sciences, Hainan, China). The primers were synthesized by Yingjun Life Technologies (Shanghai, China) and the following sequences were used, with the restriction sites underlined: $\mathrm{P} 1,5^{\prime}-\mathrm{CA}$ CCATGGCAACTGTGTTCTCGGCGCTGTTGC-3' and P2, 5'-TCCTCGAGTCGGCTCAGCTCTTCCTCTCGTTG-3'. SenX3 was amplified from the genomic DNA of the MTB strain H37Rv by polymerase chain reaction (PCR) using Pyrobest DNA polymerase (Takara Biotechnology, Dalian, China) as well as forward and reverse primers. PCR cycling conditions were as follows: $94^{\circ} \mathrm{C}$ for $2 \mathrm{~min} ; 30$ cycles at $94^{\circ} \mathrm{C}$ for $30 \mathrm{sec}, 55^{\circ} \mathrm{C}$ for $30 \mathrm{sec}, 72^{\circ} \mathrm{C}$ for $90 \mathrm{sec}$ and $72^{\circ} \mathrm{C}$ for $10 \mathrm{~min}$. 
The amplicon was separated by gel electrophoresis. Correctly sized products were excised and purified with a gel extraction kit (CoWin Biotech Co., Ltd., Beijing, China). The purified and confirmed PCR product was ligated into the pMD18-T vector using a DNA ligation kit (D6023; Takara Biotechnology). The resulting pMD18-T-SenX3 construct was transformed into E. coli $\mathrm{DH} 5 \alpha$-competent cells. The cells were then cultured at $37^{\circ} \mathrm{C}$ overnight on LB-ampicillin $(100 \mathrm{mg} / \mathrm{l})$ plates. Individual colonies were selected and screened by colony PCR using a vector sequencing primer.

Site-directed mutagenesis of an internal NcoI site in SenX3. Site-directed mutagenesis was used as previously described (10) to mutate an internal NcoI site within SenX3 (Fig. 1A). The primers were synthesized by Yingjun Life Technologies and the sequences used were as follows: P3, 5'-GAGTAGAGCCATCGCACCGACGGG-3' and P4, 5'-CCCGTCGGTGCGATGGCTCTACTC-3'. The PCR cycling conditions for P1-P3 primer amplification from pMD18-T-Sen X3 were as follows: $94^{\circ} \mathrm{C}$ for $2 \mathrm{~min}$; 30 cycles at $94^{\circ} \mathrm{C}$ for $30 \mathrm{sec}, 55^{\circ} \mathrm{C}$ for $30 \mathrm{sec}, 72^{\circ} \mathrm{C}$ for $30 \mathrm{sec}$ and $72^{\circ} \mathrm{C}$ for $10 \mathrm{~min}$. The cycling conditions for $\mathrm{P} 2-\mathrm{P} 4$ primer amplification from pMD18-T-SenX3 were as follows: 30 cycles of $94^{\circ} \mathrm{C}$ for $30 \mathrm{sec}, 55^{\circ} \mathrm{C}$ for $30 \mathrm{sec}, 72^{\circ} \mathrm{C}$ for $35 \mathrm{sec}$ and $72^{\circ} \mathrm{C}$ for $10 \mathrm{~min}$. The P1-P2 primers were then used to amplify a 1:1 mixture of the $\mathrm{P} 1-\mathrm{P} 3 / \mathrm{P} 2-\mathrm{P} 4 \mathrm{PCR}$ products in the following conditions: $94^{\circ} \mathrm{C}$ for $2 \mathrm{~min} ; 30 \mathrm{cycles}$ at $94^{\circ} \mathrm{C}$ for $30 \mathrm{sec}, 55^{\circ} \mathrm{C}$ for $30 \mathrm{sec}$, $72^{\circ} \mathrm{C}$ for $90 \mathrm{sec}$ and $72^{\circ} \mathrm{C}$ for $10 \mathrm{~min}$. The final PCR products were separated by gel electrophoresis and purified with a gel extraction kit (CoWin Biotech Co., Ltd.). The purified product was ligated back into pMD18-T to yield pMD18-T-mSenX3, which was then transformed into $E$. coli DH5 $\alpha$-competent cells (11). Individual colonies were screened by colony PCR.

Cloning SenX3 into the prokaryotic expression vector pET-28b. pMD18-T-mSenX3 and the prokaryotic expression vector pET-28b(+) were digested with $\mathrm{NcoI}$ and $\mathrm{XhoI}$ restriction endonucleases (Takara Biotechnology) to produce compatible ends. The products were separated by gel electrophoresis, purified with a gel extraction kit (CoWin Biotech Co., Ltd.) and ligated together with $\mathrm{T}_{4}$ DNA ligase (Takara Biotechnology) at $16^{\circ} \mathrm{C}$ overnight. The ligated vector was transformed into $E$. coli DH5 $\alpha$-competent cells and grown overnight on LB-kanamycin $(50 \mathrm{mg} / \mathrm{l})$ plates at $37^{\circ} \mathrm{C}$. Individual colonies were selected and the recombinant pET-28b-mSenX3 plasmid was purified and confirmed by restriction digestion. Following identification, pET-28b-mSenX3 was transformed into E. coli BL21 (DE3) and grown overnight on LB-kanamycin $(50 \mathrm{mg} / \mathrm{l})$ plates at $37^{\circ} \mathrm{C}$. Individual colonies were selected and confirmed by PCR with P1 and P2 primers (11).

Expression of recombinant SenX3. Recombinant expression strains were inoculated in $20 \mathrm{ml}$ of LB-kanamycin $(50 \mathrm{mg} / \mathrm{l})$ broth and grown at $37^{\circ} \mathrm{C}$ overnight. Overnight cultures were diluted 1:100 in $50 \mathrm{ml}$ of fresh LB-kanamycin $(50 \mathrm{mg} / \mathrm{l})$ broth and cultured with agitation at $37^{\circ} \mathrm{C}$ until the $\mathrm{OD}_{600}$ was 0.6-0.8. The cultures were then divided: Protein expression was induced in one half with $0.1 \mathrm{mM}$ isopropyl $\beta$-D-thiogalactoside (IPTG) the other half was an uninduced control. The cultures were induced at either 28 or $37^{\circ} \mathrm{C}$ to

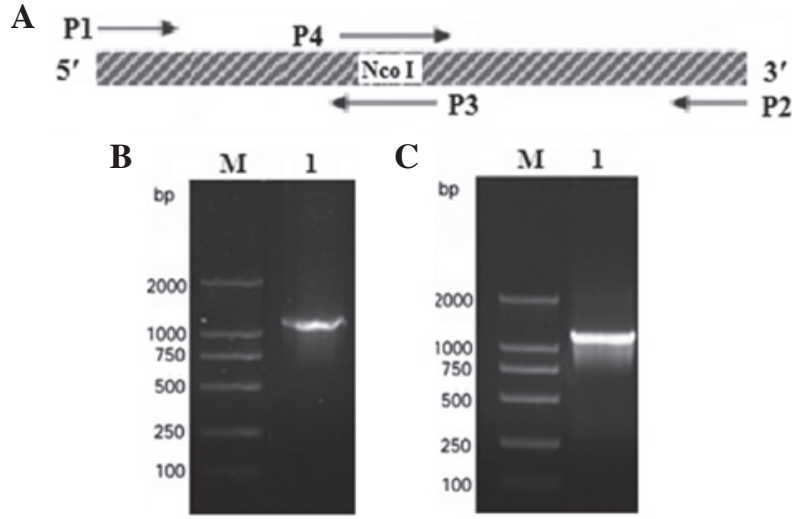

Figure 1.PCR amplification of SenX3. (A) Schematic overview of site-directed mutagenesis of SenX3 by PCR overlap extension. (B) PCR amplification of SenX3. (C) PCR amplification of SenX3 by overlap extension. M, DL2000 marker; 1 , PCR product. PCR, polymerase chain reaction.

optimize protein expression. For the analysis of protein induction, 1-ml samples were collected after $2 \mathrm{~h}$ and centrifuged at $5,000 \mathrm{x} \mathrm{g}$ at room temperature for $5 \mathrm{~min}$. Pellets were resuspended in buffer [50 mM Tris- $\mathrm{HCl}, 5 \mathrm{mM}$ EDTA, $100 \mathrm{mM}$ $\mathrm{NaCl}$ ( $\mathrm{pH}$ 8.0)] and the cells were lysed by ultrasonic homogenization. The lysates were centrifuged at $12,000 \mathrm{x}$ g at $4^{\circ} \mathrm{C}$ for $10 \mathrm{~min}$. The supernatant and precipitate were collected, denatured at $100^{\circ} \mathrm{C}$ for $5 \mathrm{~min}$ and analyzed by SDS-PAGE and Coomassie Blue.

Purification of recombinant SenX3. For protein purification, pellets were resuspended in buffer [20 mM Tris- $\mathrm{HCl}, 150 \mathrm{mM}$ $\mathrm{NaCl}$ ( $\mathrm{pH}$ 7.4)] and the cells were lysed by ultrasonic homogenization. Inclusion bodies were collected by high-speed centrifugation $(12,000 \mathrm{rpm})$ and dissolved in $8 \mathrm{M}$ carbamide buffer, followed by centrifugation at 12,000 rpm for $1 \mathrm{~h}$. The supernatant was removed and purified using Ni-NTA affinity chromatography (Invitrogen Life Technologies, Carlsbad, CA, USA). The proteins were eluted with 50,150 or $250 \mathrm{mM}$ imidazole and fractions were collected and analyzed by SDS-PAGE to determine the optimal elution conditions. Eluted proteins were diluted in renaturation buffer [50 mM Tris- $\mathrm{HCl}, 200 \mathrm{mM}$ carbamide, $1 \%$ glycerol, $0.5 \mathrm{mM}$ EDTA (pH 7.9)], incubated at $4^{\circ} \mathrm{C}$ overnight and centrifuged at $12,000 \mathrm{rpm}$ for $10 \mathrm{~min}$. Precipitates were removed and the solution was concentrated by ultrafiltration.

Western blot analysis. Purified recombinant SenX3 was separated by SDS-PAGE and transferred onto nitrocellulose membranes for western blot analysis with an anti-6X His Tag primary antibody (CoWin Biotech Co., Ltd.). Signals were detected by conjugation to a horseradish peroxidase (HRP)-labeled goat anti-mouse IgG secondary antibody (CoWin Biotech Co., Ltd.) and visualized with an HRP-3,3'diaminobenzidine tetrahydrochloride (DAB) substrate chromogenic kit (CoWin Biotech Co., Ltd.).

\section{Results}

Site-directed mutagenesis to eliminate an internal NcoI site within SenX3. In accordance with GenBank (accession 
A

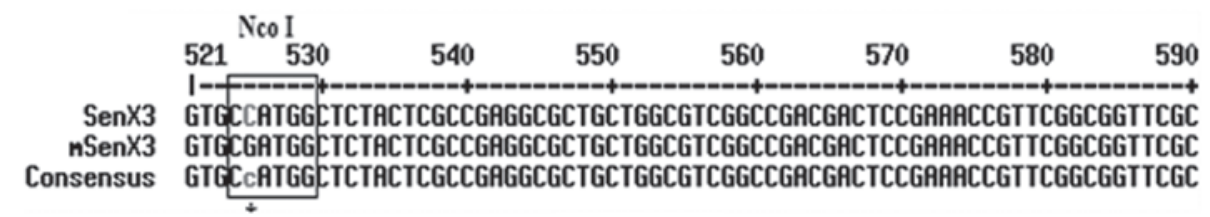

B

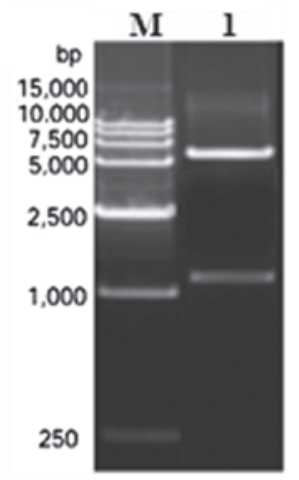

Figure 2. Restriction digestion analysis of pET-28b-mSenX3 with $N c o$ I and XhoI. (A) Sequence alignment of SenX3 and $m S e n X 3$ with the NcoI restriction site boxed. (B) Restriction digestion analysis of pET-28b-mSenX3 with NcoI and XhoI. M, DL15000 marker; 1, restriction-digested pET-28b-mSenX3.

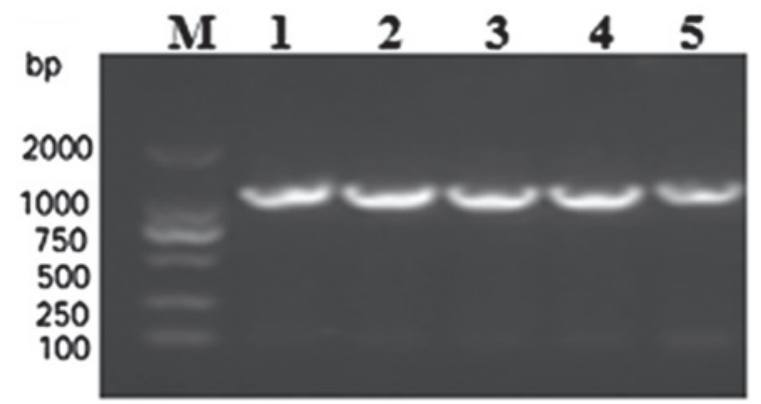

Figure 3. Clone confirmation of pET-28b-mSenX3 by colony PCR. M, DL2000 marker; 1-5, positive clones. PCR, polymerase chain reaction.

no. Y13628.1), PCR amplification of the genomic DNA of the MTB strain H37Rv generated a 1,233-bp SenX3 DNA fragment (Fig. 1B). This product was cloned into the pMD-18T vector to generate pMD18-T-SenX3, which was confirmed by colony PCR identification and sequencing. Analysis of the SenX3 fragment with Vector NIT 9 software revealed an $\mathrm{NcoI}$ restriction site at $524-529 \mathrm{bp}$; to clone the SenX3 fragment within the pET-28b(+) NcoI and XhoI sites, the internal $\mathrm{NcoI}$ site within $\operatorname{SenX} 3$ had to be destroyed by site-directed mutagenesis. Overlapping PCRs were designed to induce a synonymous mutation into the internal $N c o$ I site (Fig. 1C). Diagnostic cloning and sequencing results demonstrated that the restriction site was mutated (Fig. 2A); the mutated vector was named pMD18-T-mSenX3.

Identification of the prokaryotic expression vector $p E T-28 b$ $m S e n X 3$. After mutating the internal $N c o$ I site, $m S e n X 3$ was digested from the pMD18-T-mSenX3 vector by double digestion with $\mathrm{NcoI}$ and $\mathrm{XhoI}$ restriction endonucleases. The isolated fragment was then ligated into the prokaryotic expression vector pET-28b(+) following similar digestion with $\mathrm{NcoI}$ and $X h o I$ to create compatible ends, generating pET-28b-mSenX3. Diagnostic digestion with $N c o I$ and XhoI confirmed this construct (Fig. 2B). Sequencing results also confirmed that

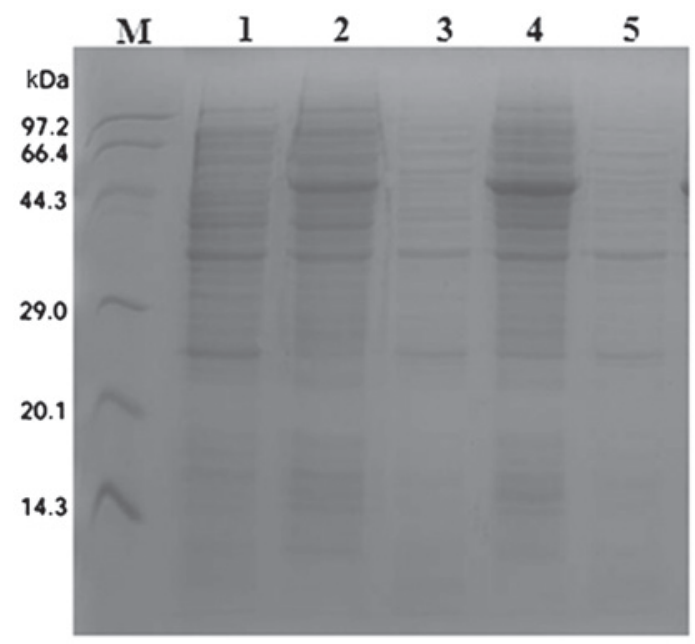

Figure 4. SDS-PAGE analysis of SenX3 induction from E. coli using Coomassie Blue. M, low molecular weight protein marker; 1, pre-induction sample; 2, ultrasonic precipitate post-induction at $28^{\circ} \mathrm{C} ; 3$, ultrasonic supernatant post-induction at $28^{\circ} \mathrm{C} ; 4$, ultrasonic precipitate post-induction at $37^{\circ} \mathrm{C}$; 5, ultrasonic supernatant post-induction at $37^{\circ}$ C. E. coli, Escherichia coli.

the open reading frame of $m \operatorname{SenX} 3$ was correct. Finally, the confirmed pET-28b-mSenX3 vector was transformed into E. coli BL21 (DE3) and confirmed by colony PCR identification (Fig. 3).

Expression of recombinant SenX3. Expression of SenX3 was induced from E. coli by treatment with IPTG, and soluble (supernatant) and insoluble (precipitate) proteins were separated by ultrasonication. Analysis by SDS-PAGE and Coomassie staining indicated the appearance of a band $\sim 46 \mathrm{kDa}$ (expected size) following IPTG induction in the precipitate lanes only (Fig. 4).

Purification of recombinant SenX3. Following induction, the ultrasonicated precipitate was collected, solubilized and purified by Ni-sepharose affinity chromatography, from which 


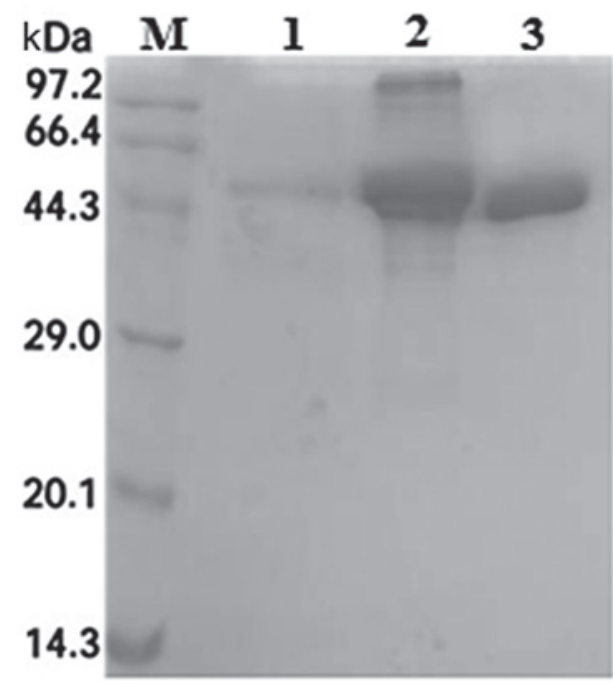

Figure 5. SDS-PAGE analysis following purification of recombinant SenX3 by $\mathrm{Ni}$-sepharose affinity chromatography using Coomassie Blue. M, low molecular weight protein marker; $1-3$, fractions eluted with 50,150 or $250 \mathrm{mM}$ imidazole, respectively.

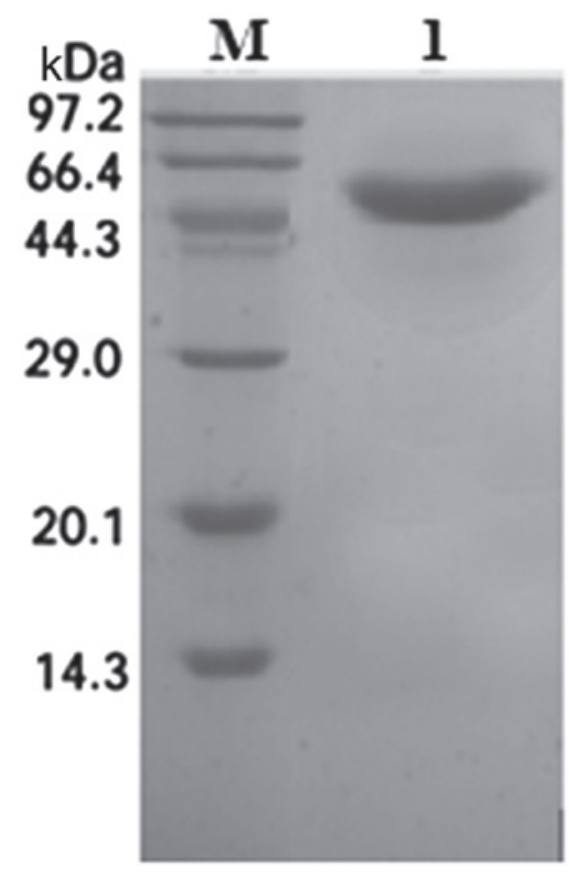

Figure 6. SDS-PAGE analysis of concentrated and refolded SenX3 using Coomassie Blue. M, low molecular weight protein marker; 1, concentrated and refolded SenX3.

protein fractions were collected and analyzed by SDS-PAGE. SenX3 was eluted at an optimal concentration of $250 \mathrm{mM}$ imidazole (Fig. 5). SDS-PAGE analysis and Coomassie staining indicated one band of the expected size of $46 \mathrm{kDa}$ (Fig. 6). Western blot analysis with an anti-6X His Tag antibody also detected a band of $\sim 46 \mathrm{kDa}$ (Fig. 7).

\section{Discussion}

SenX3/RegX3 is a TCSS transmembrane sensor that coordinates pathogen environmental responses. Parish et al (7)

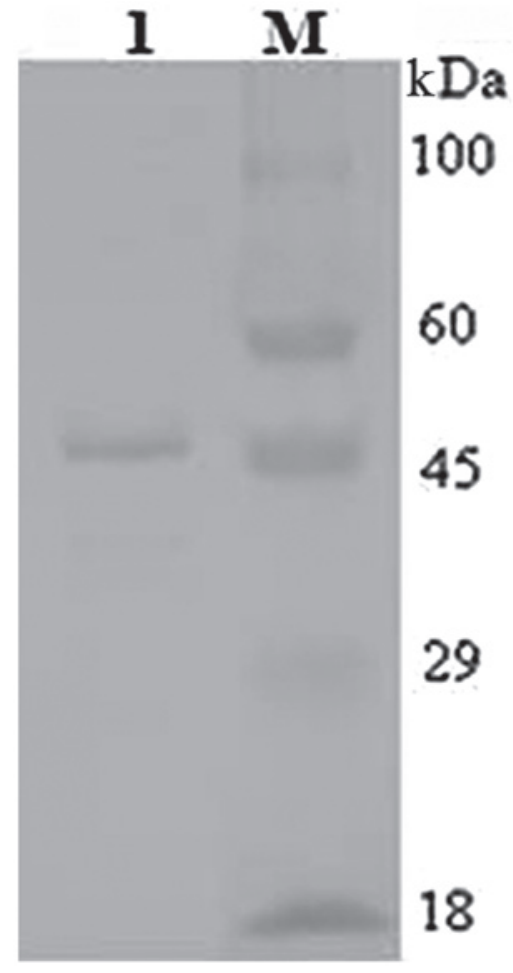

Figure 7. Western blot analysis of purified SenX3 using an anti-6X His Tag antibody. 1, Purified SenX3; M, prestained protein marker.

constructed MTB strains mutated for SenX3/RegX3 that were shown to infect human THP-1 macrophage-like cells and to gradually grow in $\gamma$-interferon-activated, bone marrow-derived murine macrophages. These strains were also shown to infect the lungs of mice and significantly decrease splenic function.

MTB strains mutated for either SenX3 or RegX3 have been shown to exhibit decreased virulence similar to MTB strains mutated for SenX3 and RegX3 (8), suggesting that regulatory mechanisms of the SenX3/RegX3 signaling pathway are important for MTB virulence. Furthermore, understanding the functions of SenX3/RegX3 and additional MTB TCSS proteins is of great significance for enabling the identification of the underlying molecular mechanisms of MTB resistance, the clinical treatment of tuberculosis, the identification of novel drugs and controlling the prevalence of drug-resistant strains $(12,13)$. According to Himpens et al (13), cytoplasmic SenX3 from Mycobacterium smegmatis was expressed using the pQE30 prokaryotic expression system. To the best of our knowledge, this was the first study to report the exogenous expression of MTB SenX3.

In the present study, PCR techniques were used to clone the genomic sequence of MTB SenX3, and SenX3 was purified from $E$. coli using affinity chromatography. The results of the present study provide important data for the future investigation of SenX3 and the molecular mechanisms of MTB resistance.

\section{Acknowledgements}

This study was supported by the Zhejiang Provincial Natural Science Foundation (grant no. Y2100445). 


\section{References}

1. Maxmen A: TB drugs chalk up rare win. Nature 487: 413-414 2012.

2. World Health Organization: Multidrug and extensively drugresistant TB (M/XDR-TB): 2010 global report on surveillance and response. World Health Organization, Geneva, Switzerland, 2010.

3. Crunkhorn S: Trial watch: Novel antimicrobial fights TB resistance. Nat Rev Drug Discov 11: 590, 2012.

4. Kalokhe AS, Shafiq M, Lee JC, Ray SM, Wang YF, Metchock B, Anderson AM and Nguyen ML: Multidrug-resistant tuberculosis drug susceptibility and molecular diagnostic testing. Am J Med Sci 345: 143-148, 2013.

5. Bretl DJ, Demetriadou C and Zahrt TC: Adaptation to environmental stimuli within the host: two-component signal transduction systems of Mycobacterium tuberculosis. Microbiol Mol Biol Rev 75: 566-582, 2011.

6. Cole ST, Brosch R, Parkhill J, et al: Deciphering the biology of Mycobacterium tuberculosis from the complete genome sequence. Nature 393: 537-544, 1998.

7. Parish T, Smith DA, Roberts G, Betts J and Stoker NG: The senX3-regX3 two-component regulatory system of Mycobacterium tuberculosis is required for virulence. Microbiology 149: 1423-1435, 2003.
8. Rickman L, Saldanha JW, Hunt DM, et al: A two-component signal transduction system with a PAS domain-containing sensor is required for virulence of Mycobacterium tuberculosis in mice. Biochem Biophys Res Commun 314: 259-267, 2004.

9. Rifat D, Bishai WR and Karakousis PC: Phosphate depletion: a novel trigger for Mycobacterium tuberculosis persistence. J Infect Dis 200: 1126-1135, 2009.

10. An Y, Ji J, Wu W, Lv A, Huang R and Wei Y: A rapid and efficient method for multiple-site mutagenesis with a modified overlap extension PCR. Appl Microbiol Biotechnol 68: 774-778, 2005.

11. Green MR and Sambrook J (eds): Molecular Cloning: A Laboratory Manual. 4th edition. Cold Spring Harbor Laboratory Press: Cold Spring Harbor, New York, 2012.

12. Carroll P, Faray-Kele MC and Parish T: Identifying vulnerable pathways in Mycobacterium tuberculosis by using a knockdown approach. Appl Environ Microbiol 77: 5040-5043, 2011.

13. Himpens S, Locht C and Supply P: Molecular characterization of the mycobacterial SenX3-RegX3 two-component system: evidence for autoregulation. Microbiology 146: 3091-3098, 2000. 